\title{
A Coupled Dynamic Index for ENSO Periodicity ${ }^{\circ}$
}

\author{
Bo LU \\ Laboratory for Climate Studies, National Climate Center, China Meteorological Administration, Beijing, and \\ CMA-NJU Joint Laboratory for Climate Prediction Studies, School of Atmospheric Sciences, Nanjing University, Nanjing, China
}

FEI-FEI JIN

Department of Atmospheric Sciences, University of Hawai'i at Mānoa, Honolulu, Hawaii, and Laboratory for Climate Studies, National Climate Center, China Meteorological Administration, Beijing, China

\section{HONG-Li REN}

Laboratory for Climate Studies, National Climate Center, China Meteorological Administration, Beijing, and CMA-NJU Joint Laboratory for Climate Prediction Studies, School of Atmospheric Sciences, Nanjing University, Nanjing, and Department of Atmospheric Science, School of Environmental Studies, China University of Geosciences, Wuhan, China

(Manuscript received 14 July 2017, in final form 20 November 2017)

\begin{abstract}
El Niño-Southern Oscillation (ENSO) is the most active interannual climatic mode, with great global impacts. The state-of-the-art climate models can simulate this dominant mode variability to a large extent. Nevertheless, some of ENSO's fundamental time-space characteristics still have a large spread in the simulations across the array of recent climate models. For example, the large biases of ENSO periodicity still exist among model simulations from phase 5 of the Coupled Model Intercomparison Project (CMIP5). Based on the recharge oscillator framework, a coupled dynamic index for ENSO periodicity is proposed in this study, referred to as the Wyrtki index, in parallel to the Bjerknes index for ENSO instability. The Wyrtki index provides an approximate dynamic measure for ENSO linear periodicity. It has two main contribution terms: the thermocline and zonal advective feedbacks (or $F$ factor) multiplied by the efficiency factor $B$ of discharging-recharging of the equatorial heat content driven by ENSO wind stress anomalies. It is demonstrated that the diversity of simulated ENSO periodicity in CMIP5 models results from the biases in mean state and several key parameters that control ENSO dynamics. A larger $F$ factor would result in a shorter ENSO period [e.g., BCC_CSM1.1(m)], whereas a smaller $B$ factor would lead to a longer ENSO period (e.g., HadGEM2-ES). The Wyrtki index serves as a useful tool for a quantitative assessment of the sources for ENSO periodicity in reanalysis data and its biases in CMIP5 model simulations.
\end{abstract}

\section{Introduction}

The El Niño-Southern Oscillation (ENSO) phenomenon dominates the climate fluctuations on the interannual time scale, with its period varying from 2 to $7 \mathrm{yr}$. It has been recognized as a result of the ocean-atmosphere interaction over the tropical Pacific. Since Bjerknes' recognition of a new coupled ocean-atmosphere instability

\footnotetext{
Supplemental information related to this paper is available at the Journals Online website: https://doi.org/10.1175/JCLI-D-170466.s1.
}

Corresponding author: Fei-Fei Jin, jff@hawaii.edu for ENSO (Bjerknes 1969), theoretical studies have made great progress in understanding the dynamics of ENSO in terms of coupled instability of the tropical climate system (McCreary 1983; Philander et al. 1984; Suarez and Schopf 1988; Battisti and Hirst 1989; Cane at al 1990; Neelin 1991; Neelin and Jin 1993; Jin and Neelin 1993a,b; Jin 1997a,b; An and Jin 2000, 2001; Fedorov and Philander 2000, 2001; Bejarano and Jin 2008). Based on the simple recharge oscillator (RO) model, an approximate coupled instability index, referred to as the Bjerknes instability index, was formulated by Jin et al. (2006). This instability index has been found to be a useful tool for assessing ENSO stability and its control on ENSO amplitude in the climate models (Kim and Jin 2011; Kim et al. 2014). 
(a)

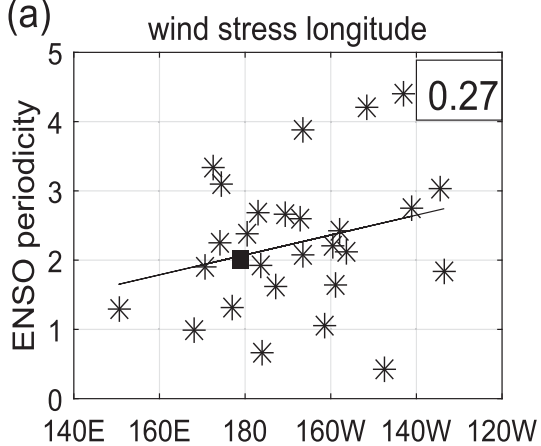

(c)

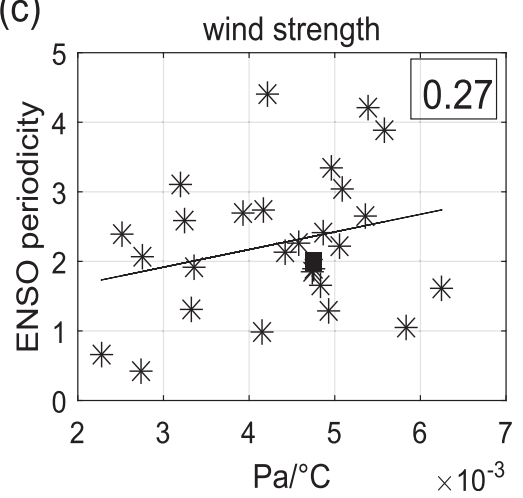

(b)

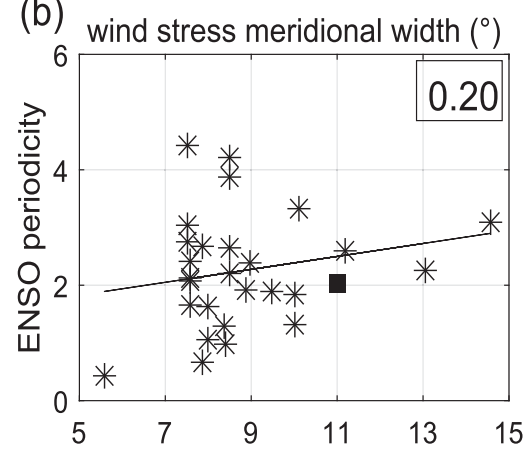

(d)

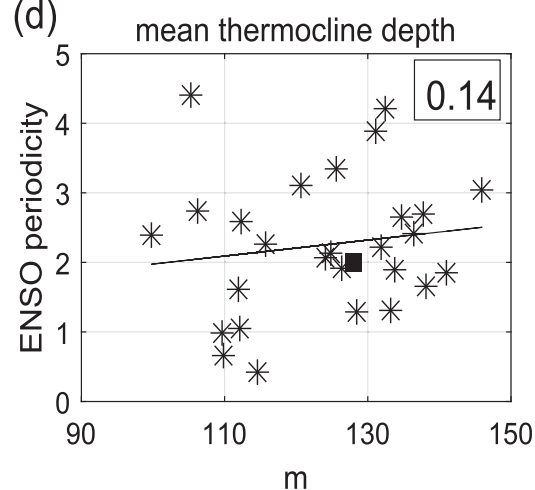

FIG. 1. Scatterplots of ENSO periodicity against (a) the longitude of ENSO-induced zonal wind stress, (b) the meridional width of ENSO-induced zonal wind stress, (c) the air-sea coupling strength, and (d) the mean thermocline depth over the eastern equatorial Pacific in each CMIP5 model (stars) and the GODAS reanalysis (black-filled squares). The regression fitting is indicated by the straight lines. Numbers in the top right denote the correlation coefficients. We adopted the metric suggested by Bellenger et al. (2014) for ENSO periodicity evaluation. First, the wavelet analysis (Morlet et al. 1982) is applied to the eastern Pacific SST. Second, ENSO spectra characteristics are further analyzed by computing the ratio between the spectral energy in the 3-8-yr band and that in the 1-3-yr band. This ratio metric serves as a more robust measure than the classic spectrum peak metric, especially when multiple peaks appear in the ENSO spectrum.

The periodicity of ENSO modes in linear stability studies has been found to be sensitively dependent on various factors, including the ENSO meridional width, longitudinal location, ocean-atmosphere coupling, and climate mean states (Cane et al. 1990; Jin and Neelin 1993a; Jin 1997b; Kirtman 1997; Kang and An 1998; Timmermann et al. 1999; Fedorov and Philander 2000; An and Wang 2000; Syu and Neelin 2000; Bejarano and Jin 2008; MacMynowski and Tziperman 2008; Stuecker et al. 2013). The linear stability analysis is able to retrieve the eigenmodes that control the broad range of simulated ENSO periodicity, although nonlinearity has been shown to alter ENSO's linear periodicity (Jin 1997b; Eccles and Tziperman 2004). Recent studies (Bellenger et al. 2014; Dommenget et al. 2014; Wang et al. 2015) have shown that the biases of feedback processes still exist in the state-of-the-art climate models that participated in phase 5 of the Coupled Model
Intercomparison Project (CMIP5; Taylor et al. 2012). As a result, large spread is evident in the simulations of ENSO periodicity (Bellenger et al. 2014). The diversity of ENSO periodicity in the CMIP5 models is not only due to statistical uncertainties, but it also reflects the inherent differences in model physics. Thus, it is important to understand the sources of ENSO periodicity biases in climate models.

As shown in Fig. 1, simulated diverse ENSO periodicity is not dominantly controlled by any known factors, such as the zonal position of zonal wind stress (An and Wang 2000), the meridional width of zonal wind stress (Kirtman 1997; Capotondi et al. 2006), the air-sea coupling strength (MacMynowski and Tziperman 2008), and the mean thermocline depth (Timmermann et al. 1999). What controls the range of periodicity of ENSO in these state-of-the-art models remains unknown and is worthy of further investigation. In this study, following 
TABLE 1. Detailed information about the CMIP5 models used in this paper. The southern and northern edges of the boxes are selected with the largest ENSO-related wind stress curl in each CMIP5 model. The southern and northern boundaries are $6^{\circ} \mathrm{S}$ and $4.5^{\circ} \mathrm{N}$ in the GODAS reanalysis. (Expansions of acronyms are available online at http://www.ametsoc.org/PubsAcronymList.)

\begin{tabular}{|c|c|c|c|c|}
\hline Modeling center & Model name & Simulation length & Southern edge & Northern edge \\
\hline Commonwealth Scientific and Industrial Research & ACCESS1.0 & $1850-2005$ & $7.5^{\circ} \mathrm{S}$ & $2.5^{\circ} \mathrm{N}$ \\
\hline $\begin{array}{l}\text { Organisation and Bureau of Meteorology, } \\
\text { Australia }\end{array}$ & ACCESS1.3 & $1850-2005$ & $5^{\circ} \mathrm{S}$ & $2.5^{\circ} \mathrm{N}$ \\
\hline \multirow[t]{2}{*}{ Beijing Climate Center, China } & BCC_CSM1.1 & $1850-2012$ & $4.2^{\circ} \mathrm{S}$ & $1.4^{\circ} \mathrm{N}$ \\
\hline & BCC_CSM1.1(m) & $1850-2012$ & $6.2^{\circ} \mathrm{S}$ & $1.7^{\circ} \mathrm{N}$ \\
\hline $\begin{array}{l}\text { Canadian Centre for Climate Modelling and } \\
\text { Analysis, Canada }\end{array}$ & CanESM2 & $1850-2005$ & $7^{\circ} \mathrm{S}$ & $1.4^{\circ} \mathrm{N}$ \\
\hline $\begin{array}{l}\text { National Center for Atmospheric Research, } \\
\text { United States }\end{array}$ & CCSM4 & $1850-2005$ & $5.2^{\circ} \mathrm{S}$ & $3.3^{\circ} \mathrm{N}$ \\
\hline \multirow{4}{*}{$\begin{array}{l}\text { Community Earth System Model contributors } \\
\text { (NSF-DOE-NCAR), United States }\end{array}$} & CESM1(BGC) & $1850-2005$ & $5.2^{\circ} \mathrm{S}$ & $3.3^{\circ} \mathrm{N}$ \\
\hline & CESM1(CAM5) & $1850-2005$ & $5.2^{\circ} \mathrm{S}$ & $3.3^{\circ} \mathrm{N}$ \\
\hline & CESM1(FASTCHEM) & $1850-2005$ & $5.2^{\circ} \mathrm{S}$ & $3.3^{\circ} \mathrm{N}$ \\
\hline & CESM1(WACCM) & $1850-2005$ & $4.7^{\circ} \mathrm{S}$ & $2.8^{\circ} \mathrm{N}$ \\
\hline \multirow{3}{*}{$\begin{array}{l}\text { Centro Euro-Mediterraneo sui Cambiamenti } \\
\text { Climatici, Italy }\end{array}$} & CMCC-CESM & $1850-2005$ & $9^{\circ} \mathrm{S}$ & $5.6^{\circ} \mathrm{N}$ \\
\hline & CMCC-CM & $1850-2005$ & $7.1^{\circ} \mathrm{S}$ & $1.9^{\circ} \mathrm{N}$ \\
\hline & CMCC-CMS & $1850-2005$ & $8.4^{\circ} \mathrm{S}$ & $4.7^{\circ} \mathrm{N}$ \\
\hline $\begin{array}{l}\text { Centre National de Recherches Météorologiques/ } \\
\text { Centre Européen de Recherche et de Formation } \\
\text { Avancée en Calcul Scientifique, France }\end{array}$ & CNRM-CM5.2 & $1850-2005$ & $4.9^{\circ} \mathrm{S}$ & $3.5^{\circ} \mathrm{N}$ \\
\hline \multirow{2}{*}{$\begin{array}{l}\text { NOAA/Geophysical Fluid Dynamics Laboratory, } \\
\text { United States }\end{array}$} & GFDL CM3 & $1860-2005$ & $7^{\circ} \mathrm{S}$ & $3^{\circ} \mathrm{N}$ \\
\hline & GFDL-ESM2M & $1861-2005$ & $7.1^{\circ} \mathrm{S}$ & $3^{\circ} \mathrm{N}$ \\
\hline \multirow{2}{*}{$\begin{array}{l}\text { NASA Goddard Institute for Space Studies, } \\
\text { United States }\end{array}$} & GISS-E2-R & $1850-2005$ & $5^{\circ} \mathrm{S}$ & $3^{\circ} \mathrm{N}$ \\
\hline & GISS-E2-R-CC & $1850-2010$ & $5^{\circ} \mathrm{S}$ & $3^{\circ} \mathrm{N}$ \\
\hline \multirow[t]{2}{*}{ Met Office Hadley Centre, United Kingdom } & HadGEM2-CC & $1860-2005$ & $5^{\circ} \mathrm{S}$ & $2.5^{\circ} \mathrm{N}$ \\
\hline & HadGEM2-ES & $1860-2005$ & $5^{\circ} \mathrm{S}$ & $2.5^{\circ} \mathrm{N}$ \\
\hline \multirow[t]{3}{*}{ L' Institut Pierre-Simon Laplace, France } & IPSL-CM5A-LR & $1850-2005$ & $4.7^{\circ} \mathrm{S}$ & $2.8^{\circ} \mathrm{N}$ \\
\hline & IPSL-CM5A-MR & $1850-2005$ & $5.1^{\circ} \mathrm{S}$ & $3.8^{\circ} \mathrm{N}$ \\
\hline & IPSL-CM5B-LR & $1850-2005$ & $6.6^{\circ} \mathrm{S}$ & $2.8^{\circ} \mathrm{N}$ \\
\hline Max Planck Institute for Meteorology, Germany & MPI-ESM-MR & $1850-2005$ & $8.4^{\circ} \mathrm{S}$ & $2.8^{\circ} \mathrm{N}$ \\
\hline Meteorological Research Institute, Japan & MRI-CGCM3 & $1850-2005$ & $5^{\circ} \mathrm{S}$ & $2.8^{\circ} \mathrm{N}$ \\
\hline \multirow[t]{2}{*}{ Norwegian Climate Centre, Norway } & NorESM1-M & $1850-2005$ & $4.7^{\circ} \mathrm{S}$ & $2.8^{\circ} \mathrm{N}$ \\
\hline & NorESM1-ME & $1850-2005$ & $4.7^{\circ} \mathrm{S}$ & $2.8^{\circ} \mathrm{N}$ \\
\hline
\end{tabular}

the approach using the formulation of the Bjerknes instability index based on the RO framework, we propose an approximate measure for ENSO linear periodicity. Moreover, we will utilize this new dynamic index to gain insights into the main causes of ENSO periodicity in the reanalysis data, as well as in the simulations of CMIP5 models.

This paper is organized as follows. Observational datasets and CMIP5 experiments are briefly introduced in section 2. The formulation of the coupled dynamic index for ENSO periodicity is derived in section 3. Section 4 further investigates the dynamic approximation of the coupled periodicity index. A summary and conclusions are presented in section 5 .

\section{Data and methodology}

NCEP Global Ocean Data Assimilation System (GODAS) data (Behringer et al. 1998) are used to represent the objective estimations of the observational monthly three-dimensional current and temperature in the ocean, as well as the momentum and heat flux at the surface since 1980 . The monthly mean output from CMIP5 models are also analyzed in this study. (All these data are available at http://pcmdi9.llnl.gov/.) Table 1 summarizes the model information, including the model names, their associated modeling centers, and their simulation lengths.

In this paper, we consider the models that provide output of three-dimensional ocean current, temperature and surface momentum, and heat flux data of historical simulations. The historical simulations use initial conditions taken from the preindustrial control experiment under full historical forcing (e.g., greenhouse gases, aerosols, ozone, volcanic aerosols, and land use). To remove decadal and longer variability, an 8 -yr running average is removed from the anomalous quantities. 


\section{Measuring periodicity of ENSO}

Following recharge-discharge oscillation framework (Jin 1997a), two prognostic equations for SST and thermocline depth anomalies can be written as

$$
\begin{aligned}
\frac{d}{d t} T_{E} & =R T_{E}+F h \quad \text { and } \\
\frac{d}{d t} h & =-\varepsilon h-B T_{E},
\end{aligned}
$$

where $T_{E}$ represents the SST anomalies averaged over the eastern equatorial Pacific $\left(170^{\circ}-90^{\circ} \mathrm{W}\right.$; meridional boundaries shown in Table 1 ), and $h$ represents the thermocline depth anomalies averaged over the entire equatorial Pacific $\left(140^{\circ} \mathrm{E}-90^{\circ} \mathrm{W}\right.$; meridional boundaries shown in Table 1). The parameter $R$ indicates the damping rate of eastern Pacific SST and is often referred to as the Bjerknes instability index (Jin et al. 2006). The parameter $\varepsilon$ denotes the damping rate of thermocline depth resulting from the energy leak at the western boundary and mixing. The parameter $F$ represents the impact of the discharged-recharged state of ocean heat content onto SST, and the parameter $B$ indicates the efficiency of the discharging-recharging of the equatorial heat content driven by ENSO SST anomalies induced by the equatorial wind stress curl anomalies. The noise forcing and nonlinear terms are omitted here for brevity.

We first examine the effectiveness of the above simple set of equations in capturing ENSO slow dynamics using the reanalysis and CMIP5 simulation data. Here, the parameters $R, F, \varepsilon$, and $B$ are calculated by linear regressions. It should be noted that this recharge oscillator model only captures essential slow and linear processes of ENSO. Various quasi-balance assumptions adopted in deriving the recharge oscillator (Jin et al. 2006) have implicitly filtered out the fast variability associated with ENSO. Therefore, as shown in Fig. 2, the tendencies of SST and thermocline depth anomalies can be well explained by this simple RO model when the highfrequency variability is filtered, for instance, by even using a simple running average. In CMIP5 simulations, the total variance of SST (thermocline depth) tendency can be explained by only $43 \%$ (30\%) without smoothing; however, the explained variance increases to $60 \%$ $(54 \%)$ if a 9-month running mean is applied. The variance of SST (thermocline depth) tendency can be explained by $47 \%(60 \%)$ when a 9 -month running mean is applied to GODAS data. It should be noted that the simulation length is about 150 years in CMIP5 historical simulations and 36 years in GODAS data, which may result in the some differences in the explained variance between the CMIP5 multimodel mean (MME) and the reanalysis data. Overall, the simple RO model indeed captures a significant portion of the slow variation of the SST and thermocline depth, even though other terms, such as nonlinearity and subgrid processes, are omitted. Hereafter, a 9-month running average will be utilized for the analysis in this paper.

Assuming a simple linear solution as $T=A e^{i \omega t}$, the ENSO period of the RO model can be obtained as $4 \pi\left[4 B F-(R+\varepsilon)^{2}\right]^{-1 / 2}$. As shown in Table 2, the term $(R+\varepsilon)^{2}$ is small in both the GODAS reanalysis and the CMIP5 models and, thus, can be neglected. Then, the period solution is simplified as

$$
I_{\mathrm{Wyrki}}=\frac{4 \pi}{\sqrt{4 B F}} .
$$

Here, we refer to $I_{\mathrm{Wyrtki}}$ as the Wyrtki index (yr) because Wyrtki (1985) first recognized ENSO phase turn as a result of equatorial heat content recharge and discharge.

Figure 3 shows the scatterplot of ENSO periodicity versus the Wyrtki index in the CMIP5 historical simulations and the GODAS reanalysis. Consistent with previous findings (Bellenger et al. 2014), there is a large spread in the simulated ENSO periods. Some models [BCC_CSM1.1, BCC_CSM1.1(m), and CNRM-CM5.2] produce ENSO with a too-short period. Other models [CCSM4, CESM1(BGC), HadGEM2-ES, and MPIESM-MR] tend to have a spectral peak displaced toward relatively longer periods. The periodicity measured by the spectrum pattern (Bellenger et al. 2014; see also the caption of Fig. 1) varies from 0.5 to 4.3 in CMIP5 historical simulations. The multimodel mean periodicity ratio is 2.2 , which is very close to the observed ratio of 2.1; both roughly correspond to a periodicity of about $3.5 \mathrm{yr}$, as measured by Wyrtki index. As shown in Fig. 3, the period diversity can be well explained by the Wyrtki index. The correlation coefficient reaches 0.86 , which is significant at the $99 \%$ level (using the Student's $t$ test). In other words, a longer (shorter) period generally corresponds to a large (smaller) Wyrtki index. Thus, the Wyrtki index can be considered a reasonable indicator for the ENSO period. Here, the Wyrtki index is fitted from the data using a simple RO model. In the next section, we will derive an approximate formulation for this index.

\section{An approximate formulation of the Wyrtki index}

As shown in Eq. (3), the ENSO periodicity index is determined by two factors: $B$ and $F$. Adopting the approach for the Bjerknes index of ENSO growth rate (Jin et al. 2006), we can derive their approximate representations. 

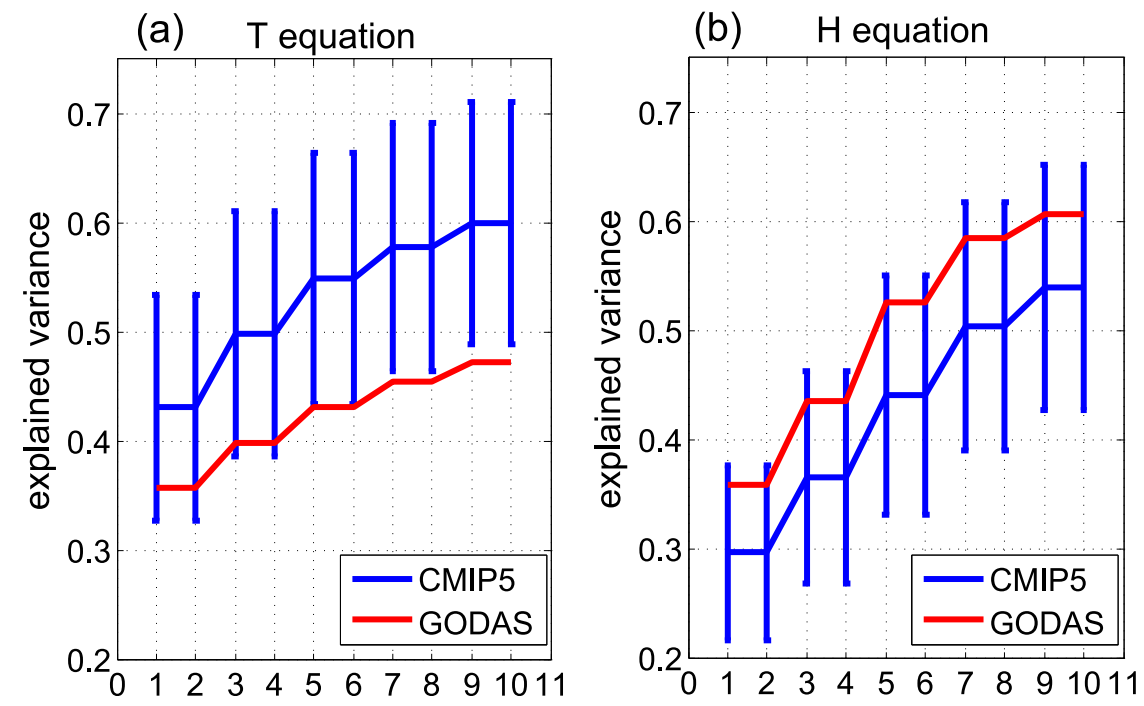

FIG. 2. The variances of the (a) SST tendency and (b) thermocline depth tendency explained by the simple RO model in Eqs. (1) and (2) as the function of smooth time (months) in the CMIP5 models (blue) and GODAS (red). The error bars indicate the standard deviations of explained variances among different CMIP5 models.

\section{a. Response of SST tendencies to the thermocline}

The $F$ factor in Eq. (1) originated from the response of SST owing to the feedback processes. We can derive an approximate representation of the parameter $F$ from the following linearized SST equation of the mixed layer:

$$
\begin{aligned}
\frac{\partial T}{\partial t}=-\left(\bar{u} \frac{\partial T}{\partial x}\right. & +\bar{v} \frac{\partial T}{\partial y}+\bar{w} \frac{\partial T}{\partial z}+u \frac{\partial \bar{T}}{\partial x} \\
& \left.+v \frac{\partial \bar{T}}{\partial y}+w \frac{\partial \bar{T}}{\partial z}\right)+Q
\end{aligned}
$$

where $T, Q, u, v$, and $w$ denote the mixed layer ocean temperature, net anomalous heat flux at sea surface, and three-dimensional ocean current anomalies. The overbars represent the climatologic mean states. We apply the box average on Eq. (4) over the equatorial centraleastern Pacific. The longitude range of this eastern Pacific box is $170^{\circ}-90^{\circ} \mathrm{W}$, and the mixed layer depth is fixed at $50 \mathrm{~m}$ for simplicity. The meridional range of the box is listed in Table 1, which will be discussed later. Following Jin et al. (2006), the box-averaged SST anomaly equation can be written as follows:

TABLE 2. The contribution terms of the Wyrtki index in the CMIP5 models and the observation.

\begin{tabular}{lcc}
\hline \hline & CMIP5 $\left(\mathrm{yr}^{-2}\right)$ & GODAS $\left(\mathrm{yr}^{-2}\right)$ \\
\hline $4 B F$ & $12.9 \pm 3.5$ & 13.1 \\
$(R+\varepsilon)^{2}$ & $0.4 \pm 0.4$ & 1.8 \\
\hline
\end{tabular}

$$
\begin{aligned}
\frac{\partial\langle T\rangle}{\partial t}= & -\left(\frac{\langle\bar{u}\rangle}{L_{x}}+\frac{\langle-2 y \bar{v}\rangle}{L_{y}}+\frac{\langle H(\bar{w}) \bar{w}\rangle}{H_{m}}\right)\langle T\rangle \\
& -\langle u\rangle\left\langle\frac{\partial \bar{T}}{\partial x}\right\rangle+\gamma\langle H(\bar{w}) \bar{w}\rangle \frac{\left\langle T_{\text {sub }}\right\rangle}{H_{m}} \\
& -\langle w\rangle\left\langle H(\bar{w}) \frac{\partial \bar{T}}{\partial z}\right\rangle+\langle Q\rangle,
\end{aligned}
$$

where $L_{x}$ and $L_{y}$ are the zonal and meridional extents of the box. The $y$ in the second term on the rhs denotes the meridional coordinate, which comes from the assumption that the SST anomalies have a Gaussian-like meridional pattern with an $e$-folding decay (Jin et al. 2006). The $H_{m}$ is the effective depth for the vertical advection, which is fixed at $75 \mathrm{~m}$ in this paper, and $T_{\text {sub }}$ is the subsurface temperature anomaly. The $H(x)$ is a step function that only considers the regions with upward vertical advection. The angle brackets denote the average of quantities over the eastern box $\left(170^{\circ}-90^{\circ} \mathrm{W}\right.$; varying meridional range in Table 1). The square brackets denote the average of quantities over the entire equatorial Pacific $\left(140^{\circ} \mathrm{E}-90^{\circ} \mathrm{W}\right.$; varying meridional range in Table 1$)$. Following the Zebiak-Cane model (Zebiak and Cane 1987), parameter $\gamma$ measures the effectiveness of the vertical entrainment. The term $v \partial \bar{T} / \partial y$ in Eq. (4) has been omitted, as in Jin et al. (2006), because the advection of the mean temperature by the anomalous meridional current is small. The nonlinear terms have also been omitted.

The terms on the rhs of Eq. (5) represent the dynamical damping process, zonal advective feedback, thermocline 


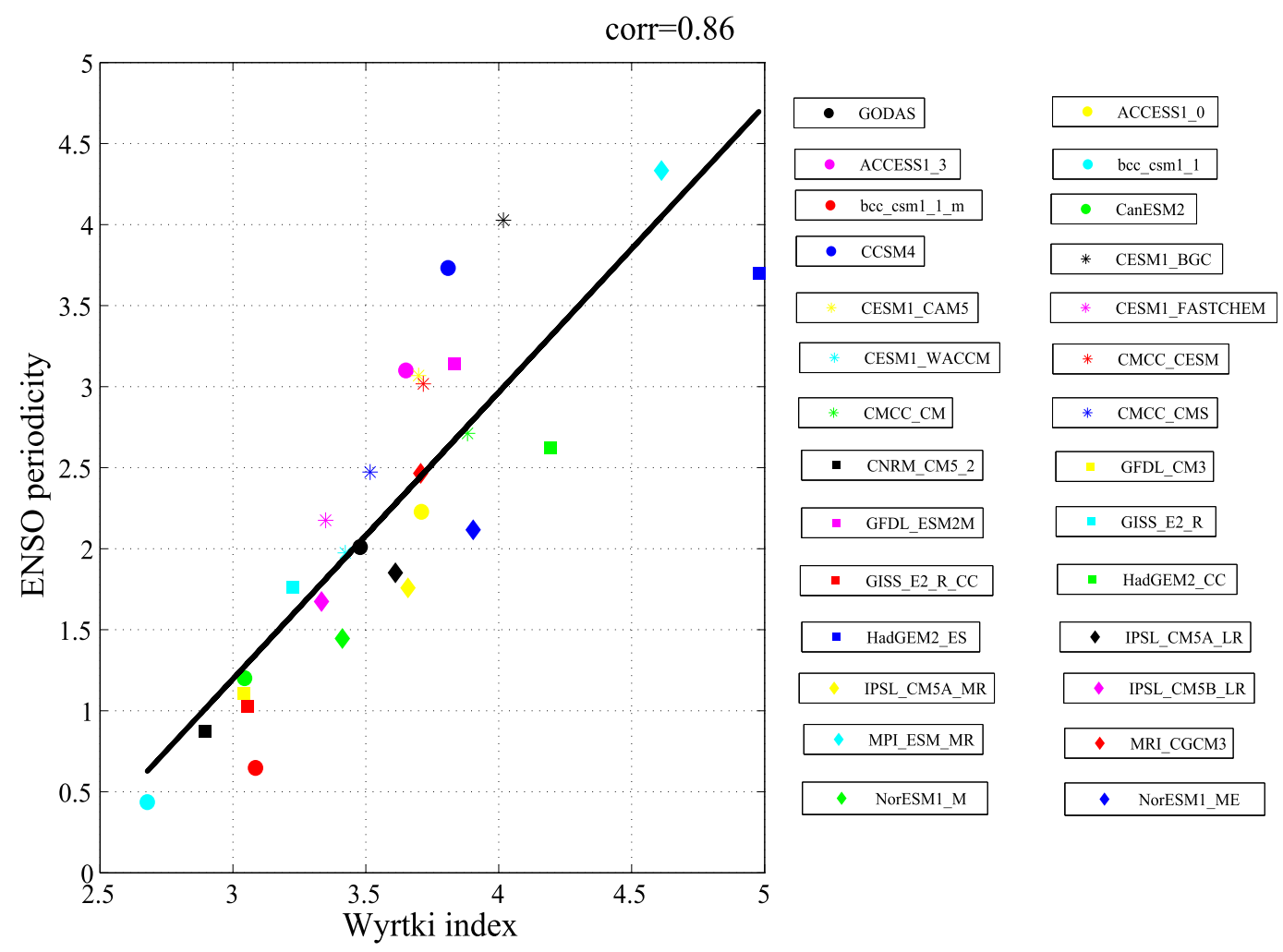

FIG. 3. Scatterplot of ENSO periodicity against the Wyrtki index (yr) in the CMIP5 historical simulations and the GODAS reanalysis. ENSO periodicity ( $y$ axis) following Bellenger et al. (2014) is nondimensional and measures the ratio of power in the 3-7-yr band over the1-3-yr band. The Wyrtki index ( $x$ axis) measures the theoretical ENSO period. The linear regression fitting is indicated by the straight line. The number at the top right denotes the correlation coefficient.

feedback, Ekman feedback, and thermal damping processes, respectively. The five terms on the rhs can be expressed as a linear function of the thermocline depth anomalies and SST anomalies. Following the quasibalance approximations proposed in Jin et al. (2006), Eq. (5) can be recast in the form of a standard RO model. First, the SST warming over the eastern Pacific will induce a westerly wind stress anomaly. We can have

$$
\left[\tau_{x}\right]=\mu_{a}\langle T\rangle .
$$

Here, $\left[\tau_{x}\right]$ denotes the zonal mean surface wind stress averaged over $140^{\circ} \mathrm{E}-90^{\circ} \mathrm{W}$. The coefficient $\mu_{a}$ is often referred to as the air-sea coupling strength. This balance equation holds very well for both CMIP5 simulations and the reanalysis data (Fig. S1 in the supplemental material). Based on the Student's $t$ test, the linear regressions are all significant at the $99 \%$ level. Although CMIP5 models tend to underestimate the wind stress response in the central Pacific (Bellenger et al. 2014), the MME coupling coefficient $\left(0.0048 \mathrm{~Pa}^{\circ} \mathrm{C}^{-1}\right)$ is close to the observed value of $0.0042 \mathrm{~Pa}^{\circ} \mathrm{C}^{-1}$ in the GODAS reanalysis.
Second, we assume that the heat flux anomalies depend on the local SST anomalies:

$$
\langle Q\rangle=-\alpha\langle T\rangle .
$$

This linear equation is often used to estimate the thermal damping rate $\alpha$. This linear relationship is robust in the models and the reanalysis data (Fig. S1). However, the MME damping rate $\alpha$ is $7.0 \mathrm{~W} \mathrm{~m}^{-2}{ }^{\circ} \mathrm{C}^{-1}$, which is only half of the observed thermal damping of $13.7 \mathrm{~W} \mathrm{~m}^{-2}{ }^{\circ} \mathrm{C}^{-1}$. This weak thermal damping is largely due to the biases in the SST-cloud-shortwave radiation feedbacks (Lloyd et al. 2011). However, we will show that the biases in thermal damping processes contribute little to the periodicity biases.

Third, the westerly wind stress $\left[\tau_{x}\right]$ reduces the upwelling in the eastern equatorial Pacific. We can obtain the following balance relationship:

$$
\langle w\rangle=-\beta_{w}\left[\tau_{x}\right] .
$$

As shown in Fig. S3 of the supplemental material, the correlation between the upwelling and the wind stress 
anomalies is weaker than the wind-SST relationship in Eq. (5). The correlation coefficient is only 0.3 in the reanalysis data. The parameter $\beta_{w}$ also exhibits large spread among the CMIP5 models. However, we will also show that this spread has little impact on the Wyrtki index, although it does impact the Bjerknes index for ENSO stability.

Fourth, following the arguments of Jin and An (1999) and Jin et al. (2006), the surface ocean current may be related to both the zonal wind stress and the upperocean pressure anomalies as follows:

$$
\langle u\rangle=\beta_{u}\left[\tau_{x}\right]+\beta_{\mathrm{uh}}[h] .
$$

Here, $[h]$ denotes the zonal mean thermocline depth over $140^{\circ} \mathrm{E}-90^{\circ} \mathrm{W}$. The coefficient $\beta_{u}$ represents the wind-driven effect, which contributes to the ENSO growth rate (Jin et al. 2006). The term $\beta_{\mathrm{uh}}[h]$ represents the geostrophic zonal current associated with the zonal mean of the equatorial heat content. Thus, $\beta_{\mathrm{uh}}$ will be a part of the $F$ factor related to ENSO periodicity. This balance relationship is quite robust in both the models and the reanalysis data (Fig. S4 in the supplemental material).

Fifth, based on the Sverdrup balance, the zonal pressure gradient induced by the tilt of thermocline is balanced by the surface wind stress on the ENSO time scale, and we obtain

$$
\langle h\rangle-[h]=\beta_{h}\left[\tau_{x}\right] .
$$

Finally, the subsurface temperature anomalies are well correlated with local thermocline depth anomalies. Without loss of generality, we have

$$
\left\langle T_{\text {sub }}\right\rangle=a_{h}\langle h\rangle .
$$

The balanced Eqs. (10) and (11) are also robust in terms of the significant correlations for both the CMIP5 simulations and the GODAS reanalysis (Figs. S5 and S6 in the supplemental material).

After applying the approximate Eqs. (6)-(11), we can reformulate Eq. (5) into a standard RO model, as in Eq. (1). The dynamic contributors of the $R$ and $F$ factors are obtained as follows:

$$
\begin{aligned}
R= & -\left(\frac{\langle\bar{u}\rangle}{L_{x}}+\frac{\langle-2 y \bar{v}\rangle}{L_{y}}+\frac{\langle H(\bar{w}) \bar{w}\rangle}{H_{m}}\right) \\
& +\mu_{a} \beta_{u}\left\langle-\frac{\partial \bar{T}}{\partial x}\right\rangle+\gamma \mu_{a} \beta_{h} a_{h}\left\langle\frac{H(\bar{w}) \bar{w}}{H_{m}}\right\rangle \\
& +\mu_{a} \beta_{w}\left\langle H(\bar{w}) \frac{\partial \bar{T}}{\partial z}\right\rangle-\alpha \text { and }
\end{aligned}
$$

TABLE 3. The partial correlation coefficients between the processes on the rhs of Eq. (5) and the thermocline depth anomalies with the impact from ENSO SST removed in the CMIP5 models MME.

\begin{tabular}{cccccc}
\hline \hline & DD & ZA & TH & EK & TD \\
\hline CMIP5 & 0 & 0.69 & 0.86 & 0 & 0.06
\end{tabular}

$F=F_{\text {adv }}+F_{\text {th }}=\beta_{\text {uh }}\left\langle-\frac{\partial \bar{T}}{\partial x}\right\rangle+\gamma a_{h}\left\langle\frac{H(\bar{w}) \bar{w}}{H_{m}}\right\rangle$.

The parameter $R$ is related to the Bjerknes index for the growth rate of ENSO. Jin et al. (2006) suggested that the dynamical damping process (DD), zonal advective feedback (ZA), thermocline feedback (TH), Ekman feedback (EK), and thermal damping processes (TD) all contribute to the Bjerknes ENSO instability. Here, it becomes clear in Eq. (13) that zonal advective and thermocline feedbacks are the main contributing processes to the $F$ factor for ENSO periodicity.

It should be noted that a two-box model here cannot explicitly take into account the zonal SST phase propagations, which may contribute to ENSO periodicity. Thus, the thermal (heat flux) damping, Ekman feedback, and dynamical damping (zonal advection by mean zonal currents) may contribute to ENSO periodicity because these processes may all contribute to zonal SST phase propagations. Nevertheless, as shown in Table 3, the dynamical damping, Ekman feedback, and thermal damping are, to a large extent, uncorrelated with the thermocline depth anomaly that has a near $-90^{\circ}$ phase difference from SST. All three processes have small phase lags with SST and, thus, have small contributions to ENSO periodicity, which supports the robustness in the formulation of Eq. (13). The dominance of the zonal advective and thermocline feedbacks in the $F$ factor is consistent with previous studies (An et al. 1999; Jin and An 1999) using the Zebiak-Cane model.

As shown in Eq. (13), the $F$ factor is controlled by the mean zonal SST gradient, mean upwelling in the climate mean state, and the coefficients of $\beta_{\mathrm{uh}}$ and $a_{h}$. The biases in the CMIP5 models are further investigated by performing intermodel correlations between the $F$ factor and its contributing terms. As shown in Fig. 4, the biases of $F_{\text {adv }}$ in the CMIP5 models are mainly due to the spread of the parameter $\beta_{\mathrm{uh}}$. Further studies show that models with weaker tropical Pacific trade winds over the central to western Pacific tend to simulate a larger $\beta_{\mathrm{uh}}$ and, thus, a stronger zonal advective feedback (Fig. 5). For the intermodel thermocline feedback $F_{\text {th }}$ biases, the contributions from the 
(a)

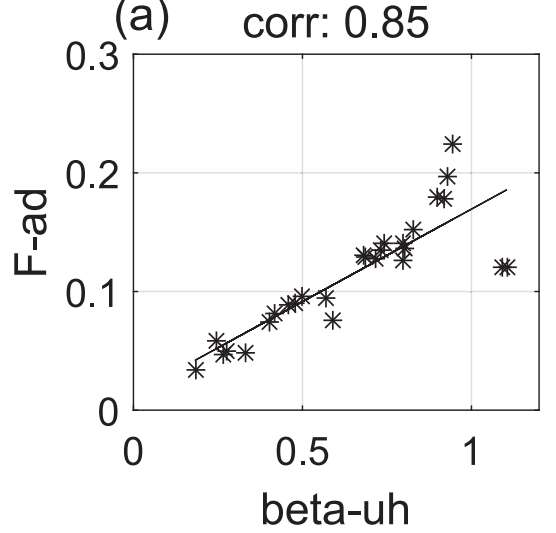

(c) corr: 0.58

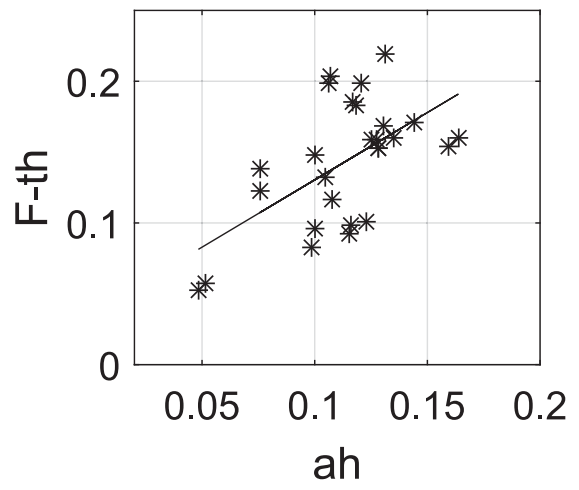

(b)

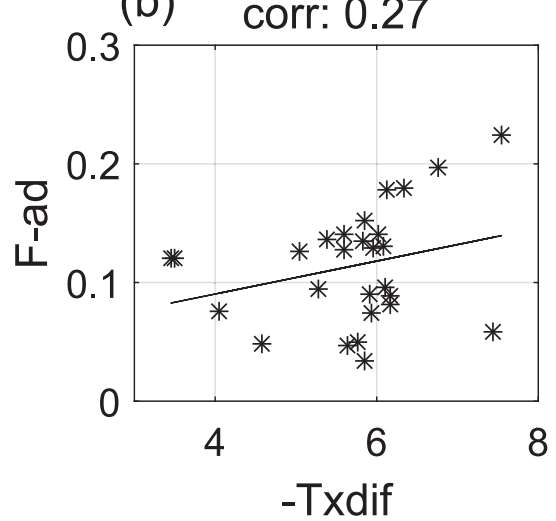

(d)

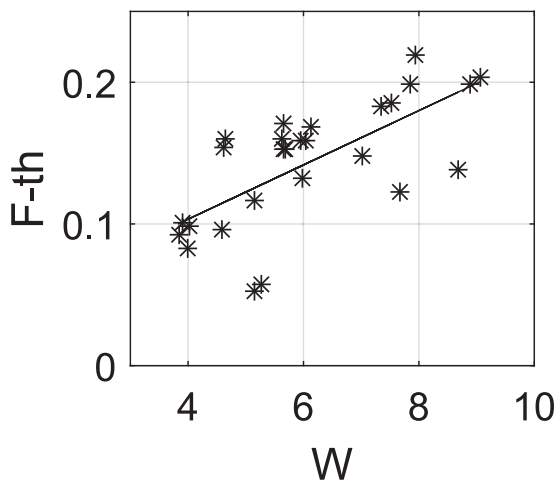

FIG. 4. Scatterplots for the zonal advective feedback $F_{\text {adv }}\left({ }^{\circ} \mathrm{C} \mathrm{yr}^{-1} \mathrm{~m}^{-1}\right)$ against (a) the parameter $\beta_{\mathrm{uh}}\left(10^{-2} \mathrm{~s}^{-1}\right)$ and (b) zonal SST gradient $\left(10^{-7}{ }^{\circ} \mathrm{Cm}^{-1}\right)$ and scatterplots for $F_{\mathrm{th}}$ $\left({ }^{\circ} \mathrm{C} \mathrm{yr}^{-1} \mathrm{~m}^{-1}\right)$ against (c) the parameter $a_{h}\left({ }^{\circ} \mathrm{C} \mathrm{m}^{-1}\right)$ and (d) mean upwelling $\left(10^{-6} \mathrm{~m} \mathrm{~s}^{-1}\right)$ in CMIP5 models. The numbers at the top of each panel denote the correlation coefficients.

parameter $a_{h}$ and the mean upwelling are generally comparable (Figs. 4c,d). The models with shallower thermocline in the eastern Pacific tend to simulate a larger $F_{\text {th }}$ (Fig. 6). We further validate this dynamical approximate formulation of the $F$ factor, as expressed by Eq. (13), by the comparison with the empirically derived $F$ values from the RO model [Eq. (1)]. As shown in Fig. 7a, the correlation coefficient between the dynamically and empirically derived $F$ values reaches 0.71 , which is significant at the $99 \%$ level using the Student's $t$ test. In other words, Eq. (13) serves as a reasonable approximate estimation for the $F$ factor. For instance, the empirically derived $F$ factor in ACCESS1.0 by the parameter fitting method is about $0.18^{\circ} \mathrm{C} \mathrm{m}^{-1} \mathrm{yr}^{-1}$, which is the smallest among all the CMIP5 models. The dynamically derived $F$ value by Eq. (13) is also the smallest. The model BCC_CSM1.1(m) has the largest empirically derived $F$ value of $0.47^{\circ} \mathrm{C} \mathrm{m}^{-1} \mathrm{yr}^{-1}$ among CMIP5 models, and its dynamic derived value is also the largest. The larger the $F$ value, the smaller the Wyrtki index and the shorter the ENSO period.
Thus, the short ENSO periodicity bias in BCC_ CSM1.1(m) partly results from the $F$ factor being too large.

\section{b. Response of thermocline tendencies to the SST}

The zonal mean thermocline depth changes, as expressed in Eq. (2), come from the recharge and discharge of warm water in the upper ocean. The wind stress curl associated with SST anomalies plays a fundamental role in this thermocline change (Jin 1997a,b; Clarke et al. 2007). As an effort to obtain an approximate estimation for the parameter $B$, we take two steps. First, we relate wind stress curl along the south and north of the equator to SST anomalies, which was taken into consideration implicitly through the meridional wind stress structure in Jin (1997a,b). Second, we follow the approach by Clarke et al. (2007) to relate the meridional mass convergence/divergence and, thus, heat content recharging and discharging, to the difference of the wind stress curl anomalies between the north and south sides of the equatorial Pacific. These two steps 

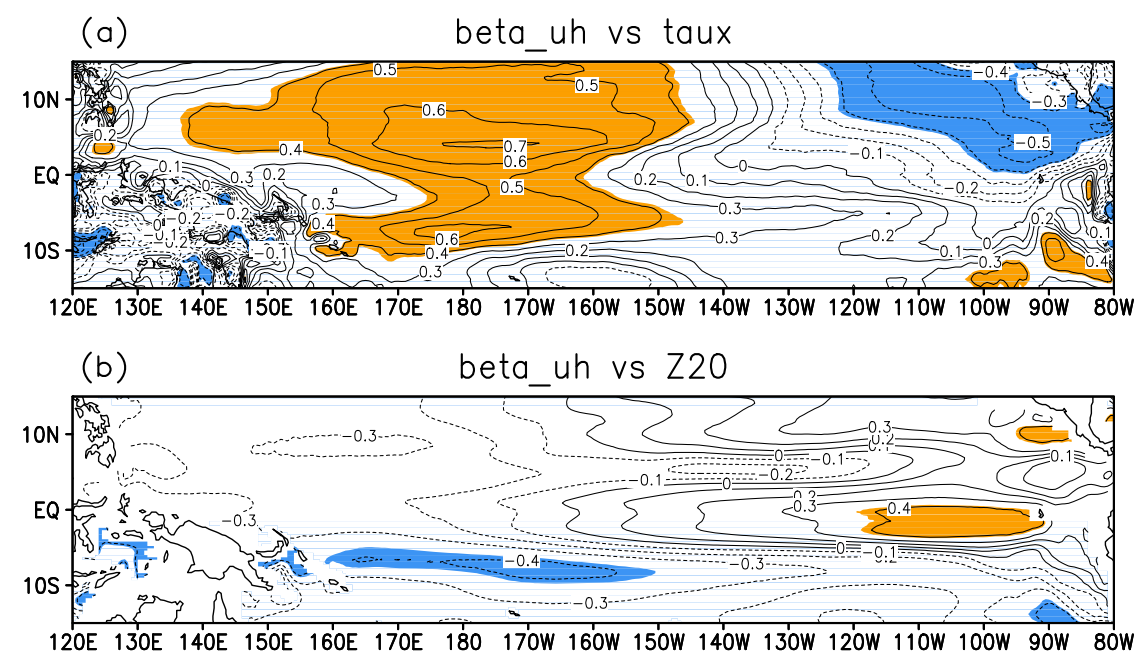

FIG. 5. Spatial patterns of intermodel correlation coefficients between the parameter $\beta_{\mathrm{uh}}$ and the (a) mean wind stress and (b) mean thermocline depth. Correlation coefficients that are significant at the $95 \%$ confidence level from the Student's $t$ test are shaded.

can be described by the following two equations, respectively:

$$
\begin{aligned}
& \left.\overline{\operatorname{curl} \boldsymbol{\tau}^{\prime}}\right|_{L_{N}}-\left.\overline{\operatorname{curl} \boldsymbol{\tau}^{\prime}}\right|_{L_{S}}=B_{1}\langle T\rangle \quad \text { and } \\
& \frac{\partial[h]}{\partial t}=-B_{2}\left(\left.\overline{\operatorname{curl} \tau^{\prime}}\right|_{L_{N}}-\left.\overline{\operatorname{curl} \boldsymbol{\tau}^{\prime}}\right|_{L_{S}}\right) .
\end{aligned}
$$

Here, $L_{S}$ and $L_{N}$ denote the southern and northern boundaries where the wind stress curl is averaged, $[h]$ represents the box-averaged thermocline depth anomalies over the entire equatorial Pacific $\left(140^{\circ} \mathrm{E}-90^{\circ} \mathrm{W}\right)$, and $\left.\overline{\operatorname{curl} \tau^{\prime}}\right|_{L_{N}}$ indicates the mean wind stress curl along the northern boundary. The detailed meridional ranges for the CMIP5 models are presented in Table 1. Given that the ENSO-induced wind stress curl pattern shows remarkable spread among the CMIP5 models
(Fig. S7 in the supplemental material), the meridional range is model dependent based on the maximum ENSO-induced wind stress pattern in each model. If wind stress curl is averaged at the fixed boundaries at $5^{\circ} \mathrm{S}-5^{\circ} \mathrm{N}$, its relations with SST anomalies [Eq. (14)] and the tendency of thermocline changes [Eq. (15)] will be very weak in some models (Fig. S8 in the supplemental material). Here, the model-dependent meridional ranges lead to more robust correlations in Eqs. (14) and (15) (Fig. S9 in the supplemental material).

As shown in Fig. 8, the wind stress curl is significantly correlated with the SST anomalies in the CMIP5 models, which gives rise to the robust estimation of the $B_{1}$ factor. In addition, the impact of wind stress curl on the thermocline tendency is pronounced among the

\section{$F$ th vs $Z 20$}

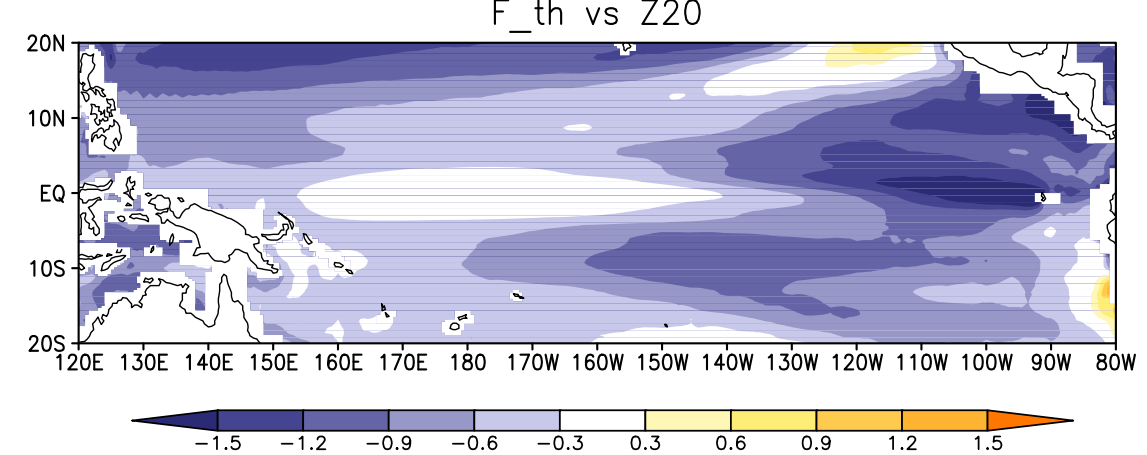

FIG. 6. The spatial pattern of the differences of mean thermocline depth (m) between the four models with the strongest thermocline feedbacks (HadGEM2-ES, NorESM1-ME, HadGEM2-CC, and NorESM1-M) and the four models with the weakest thermocline depths (ACCESS1.0, ACCESS1.3, CanESM2, and CMCC-CMS). 
(a) corr: 0.71

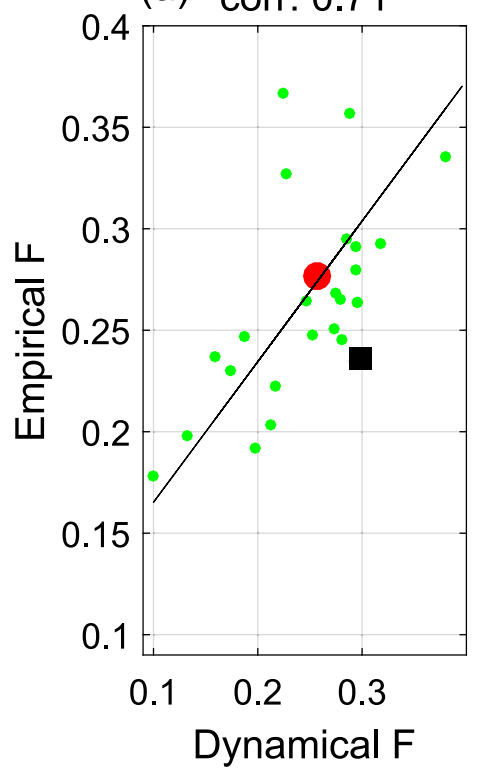

(b) corr: 0.76

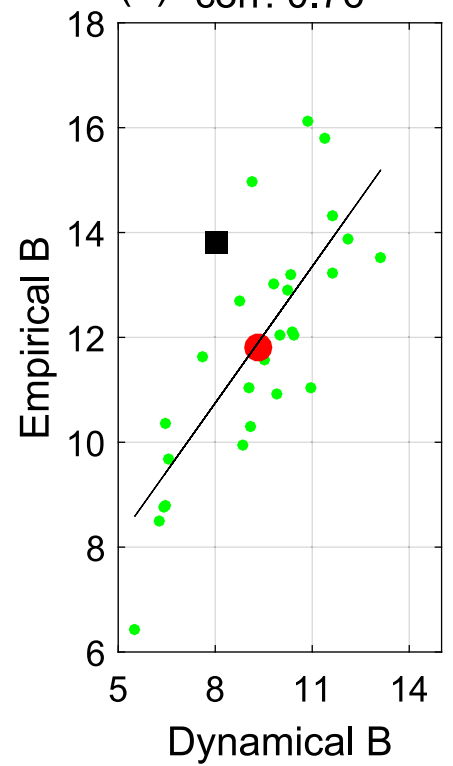

(c) corr: 0.54

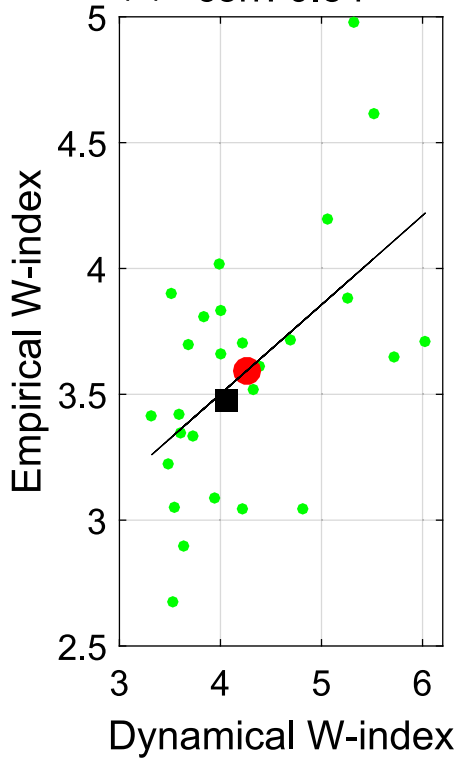

FIG. 7. (a) Scatterplot of the empirically derived $F$ factor by linear fitting in the simple RO model [Eqs. (1) and (2)] against the dynamically derived $F$ factor in Eq. (13) $\left({ }^{\circ} \mathrm{C} \mathrm{m}^{-1} \mathrm{yr}^{-1}\right)$. (b) Scatterplot of the empirically derived $B$ factor by linear fitting in the simple RO model [Eqs. (1) and (2)] against the dynamically derived $B$ factor in Eq. (16) (unit: $\mathrm{m}^{\circ} \mathrm{C}^{-1} \mathrm{yr}^{-1}$ ). (c) Scatterplot of the empirically derived Wyrtki index (yr) using the empirical $F$ and $B$ factors against the dynamically derived Wyrtki index (yr) using the dynamical $F$ and $B$ factors in the CMIP5 historical simulations (green dots) and GODAS reanalysis (black-filled squares). The multimodel mean is indicated by the red-filled circles. The linear regression fitting is indicated by the straight lines.

CMIP5 models (Fig. 9). Thus, the estimation of the $B_{2}$ factor is also robust. Combining Eqs. (14) and (15), we can easily obtain the dynamics for the parameter $B$ in Eq. (2):

$$
B=B_{1} B_{2}
$$

This two-step estimation of the $B$ factor is well correlated with direct empirical parameter fitting using the RO estimation for the $B$ factor [Eq. (2)], with the correlation coefficient reaching 0.76 (Fig. 7b). The empirically derived $B$ factor is the smallest in HadGEM2-ES, and its dynamically derived $B$ factor is also the smallest, which explains its long ENSO period (Fig. 3). This result confirms the central role of the wind stress curl in bridging the SST anomalies and the thermocline changes (Jin 1997b). It is also evident in Fig. 7b that the CMIP5 MME underestimates the $B$ factor, which suggests the underestimation of the efficiency of ENSO SST anomaly-induced equatorial heat content recharging-discharging. This lower efficiency is compensated by higher values in the simulated $F$ factor (Fig. 7a), which represents the strong SST response to the zonal mean equatorial thermocline depth. These two biases largely cancel out and lead to the rather realistic
ENSO period in the CMIP5 MME (Fig. 7c). Because biases in both $B_{1}$ and $B_{2}$ contribute to the $B$ factor in a compounding way, the relative contributions of the biases of $B_{1}$ and $B_{2}$ are examined by a $\log$-linear relationship. It is clear that intermodel biases in both $B_{1}$ and $B_{2}$ contribute significantly to the intermodel spread of the $B$ factor (Fig. 10).

As shown in Fig. 11, the $B_{1}$ factor is closely related to the ENSO-induced wind stress pattern. The larger $B_{1}$ factor in the coupled model corresponds to the stronger westerly wind stress response to ENSO along the equator and the stronger easterly wind stress response to ENSO off the equator. Thus, both the airsea coupling strength $\mu_{a}$ and the meridional width of the wind stress $L_{y}$ are of great importance to the $B_{1}$ factor. Figure 12a shows that the intermodel $B_{1}$ is highly correlated with intermodel $\mu_{a}$, with the correlation coefficient reaching 0.65 . The linear combination of $\mu_{a}$ and $L_{y}$ can explain about $58 \%$ of the total variance of the $B_{1}$ factor (Fig. 12c). Recent studies suggested that the $B_{1}$ factor is also correlated with $\beta_{h}$ among the CMIP5 models, indicating the importance of the $B_{1}$ factor in determining ENSO dynamics (An et al. 2017).

Following Clarke et al. (2007), the coefficient $B_{2}$ can be derived from the horizontal momentum equations 

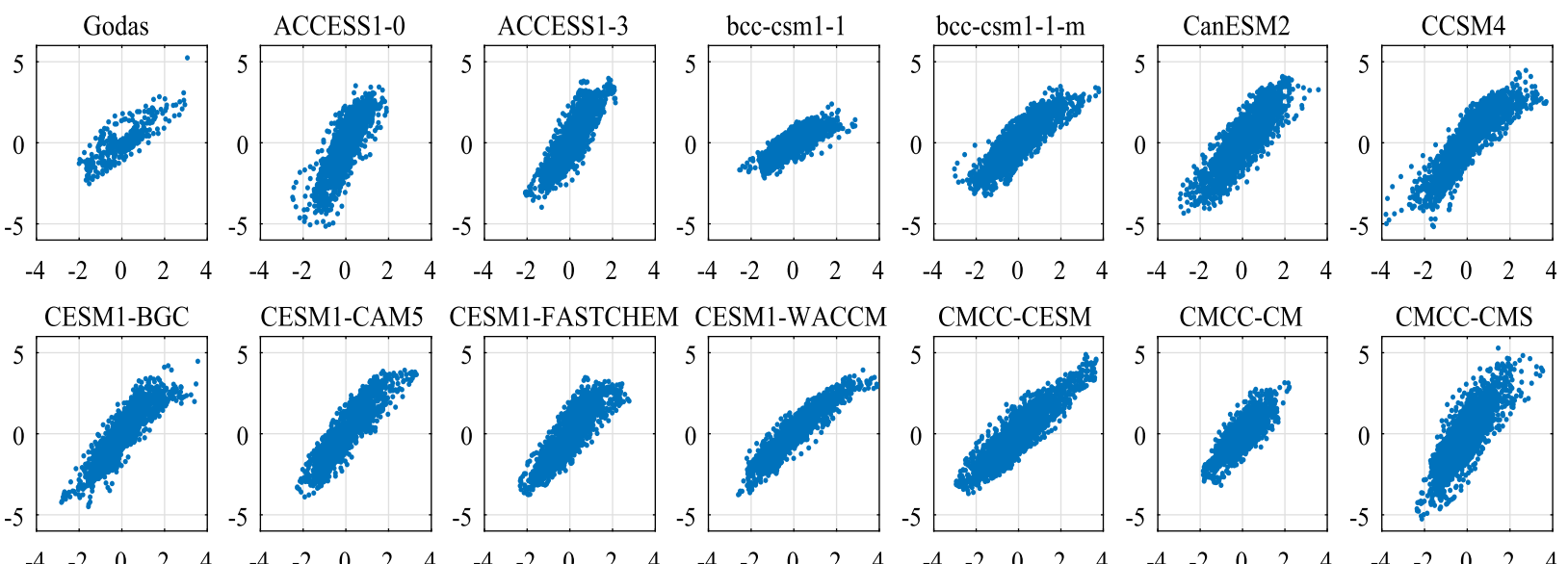

$\begin{array}{lllll}-4 & -2 & 0 & 2 & 4\end{array}$
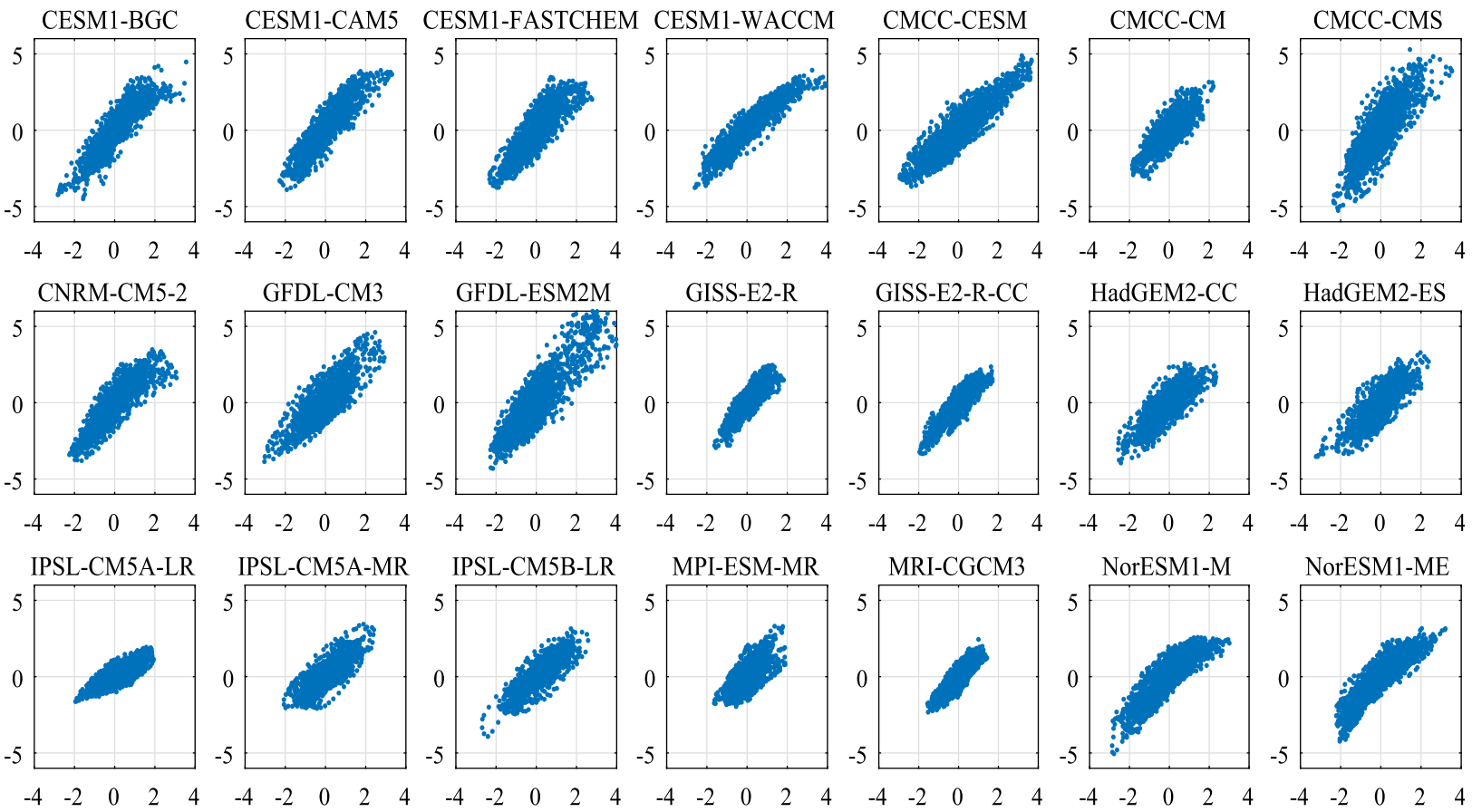

FIG. 8. Scatterplots for Eq. (14) in the CMIP5 models and GODAS reanalysis. The unit for the $x$ axis is degrees Celsius, and the unit for the $y$ axis is $10^{-8} \mathrm{~Pa} \mathrm{~m}^{-1}$.

$$
\begin{gathered}
-f v=-\frac{1}{\rho} \frac{\partial p}{\partial x}+\frac{\tau_{x}}{\rho} \quad \text { and } \\
f u=-\frac{1}{\rho} \frac{\partial p}{\partial y}+\frac{\tau_{y}}{\rho},
\end{gathered}
$$

where $\tau_{x}$ and $\tau_{y}$ denote the zonal and meridional components of wind stress, respectively, $\rho$ denotes the density, and $p$ represents the pressure. Differentiating Eq. (17) with respect to $y$ and Eq. (18) with respect to $x$, we obtain

$$
f\left(\frac{\partial u}{\partial x}+\frac{\partial v}{\partial y}\right)+\beta v=\frac{1}{\rho}\left(\frac{\partial \tau_{y}}{\partial x}-\frac{\partial \tau_{x}}{\partial y}\right) .
$$

Applying the continuity relationship, we can further have

$$
\beta v=f \frac{\partial w}{\partial z}+\frac{\operatorname{curl} \tau}{\rho}
$$

Integrating Eq. (20) from the thermocline depth $h$ to the surface, we obtain

$$
V=\frac{f}{\beta} \frac{\partial h}{\partial t}+\frac{\operatorname{curl} \tau}{\beta \rho}
$$

Neglecting the water transport at the zonal and lower boundaries, the mean thermocline changes can be expressed as

$$
\int_{A} \frac{\partial h}{\partial t} d A=\int_{0}^{L_{S}} V_{S} d x-\int_{0}^{L_{N}} V_{N} d x,
$$

where $V_{S}$ and $V_{N}$ denote the meridional current at the southern and northern edges, respectively. Applying Eq. (21) to Eq. (22), we obtain

$$
\begin{gathered}
\int_{A} \frac{\partial h}{\partial t} d A+\left(\frac{f_{N}}{\beta} \int_{0}^{L_{N}} \frac{\partial h}{\partial t} d x-\frac{f_{S}}{\beta} \int_{0}^{L_{S}} \frac{\partial h}{\partial t} d x\right) \\
=\frac{1}{\beta \rho}\left(\int_{0}^{L_{N}} \operatorname{curl} \tau^{\prime} d x-\int_{0}^{L_{S}} \operatorname{curl} \tau^{\prime} d x\right) .
\end{gathered}
$$

Clarke et al. (2007) found that the thermocline depth changes at the meridional boundaries are significantly 

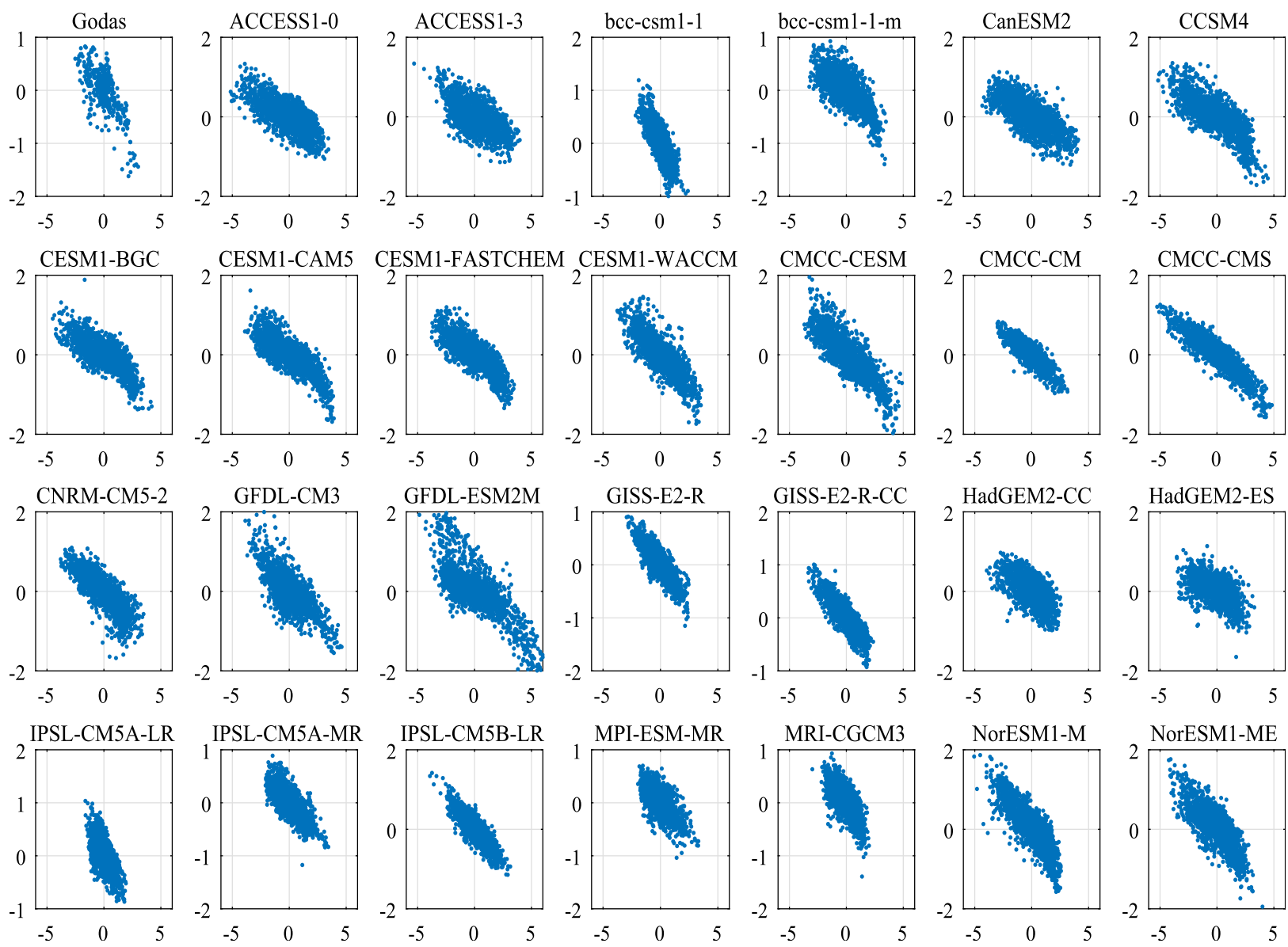

FIG. 9. Scatterplots for Eq. (15) in the CMIP5 models and GODAS reanalysis. The unit for the $x$ axis is $10^{-8} \mathrm{~Pa} \mathrm{~m}^{-1}$, and the unit for the $y$ axis is $10^{-6} \mathrm{~m} \mathrm{~s}^{-1}$.

correlated with the mean thermocline depth changes in the equatorial region

$$
\frac{f_{N}}{\beta} \int_{0}^{L_{N}} \frac{\partial h}{\partial t} d x-\frac{f_{S}}{\beta} \int_{0}^{L_{S}} \frac{\partial h}{\partial t} d x=a \int \frac{\partial h}{\partial t} d A .
$$

Thus, Eq. (23) can be written as

$$
(1+a) \frac{\partial[h]}{\partial t}=\frac{\left(\left.\overline{\operatorname{curl} \tau^{\prime}}\right|_{L_{N}}-\left.\overline{\operatorname{curl} \tau^{\prime}}\right|_{L_{S}}\right)}{\beta \rho L_{y}},
$$

where $[h]$ represents the box-averaged thermocline depth anomalies over the entire equatorial Pacific, $L_{y}$ denotes the meridional range, and $\left.\overline{\operatorname{curl} \tau^{\prime}}\right|_{L_{N}}$ indicates the mean wind stress curl along the northern boundary. Then, we can obtain the formulation of $B_{2}$ as

$$
B_{2}=\frac{1}{(1+a) \beta \rho L_{y}} .
$$

Equation (26) indicates that the parameter $B_{2}$ is affected by the meridional range of wind stress curl and the parameter $a$. If the volume of discharge-recharge water transport induced by wind stress curl is fixed, the wider meridional range will lead to the smaller thermocline changes and, thus, the longer ENSO period. The parameter $a$ is about 1 in the CMIP5 MME, which is consistent with previous findings by Clarke et al. (2007), although it varies substantially among the models.

\section{Summary and discussion}

As an effort toward understanding ENSO periodicity and its biases in climate simulations, we formulated a coupled dynamic index, referred to as the Wyrtki index, to investigate the contributing dynamical factors to ENSO periodicity. We demonstrate that this dynamically derived, semianalytical index provides a reasonable approximate estimation for ENSO main periodicity, simulated by CMIP5 models and in the reanalysis data.

The formulation of the Wyrtki index shows that ENSO periodicity mainly depends on two key factors, $F$ 
(a) corr: 0.47

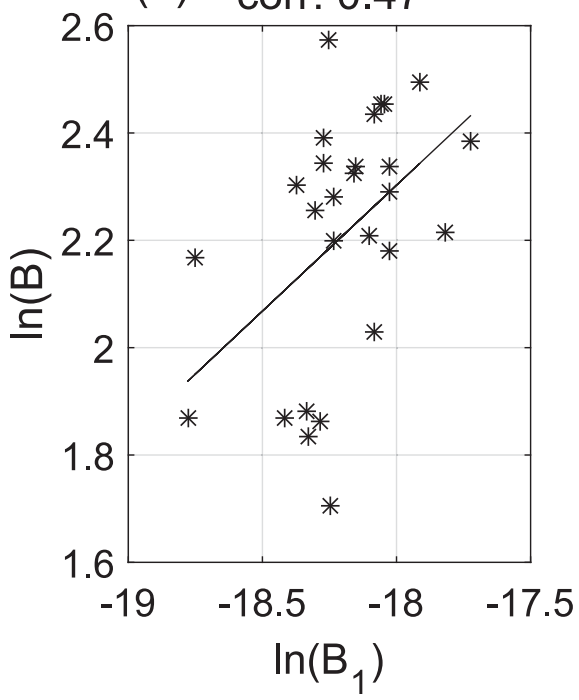

(b) corr: 0.52

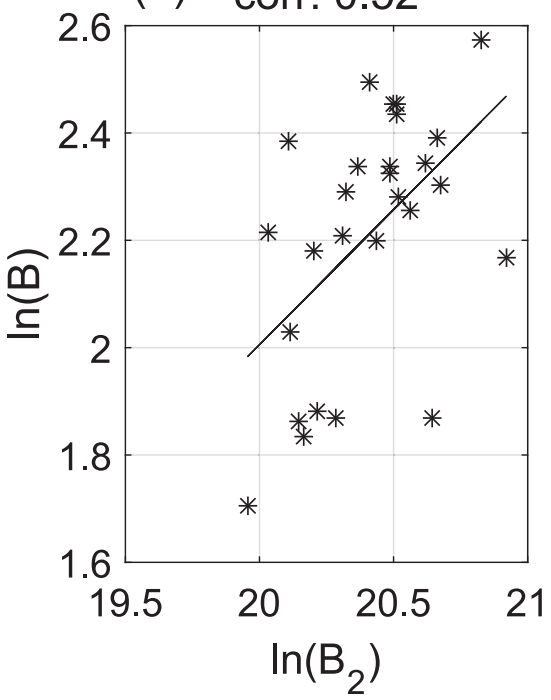

FIG. 10. Scatterplots for the natural logarithm of the $B$ factor against the natural logarithm of (a) $B_{1}$ and (b) $B_{2}$ among the CMIP5 models, with the linear fitting lines indicated. The numbers at the top of each panel denote the correlation coefficients.

and $B$, that measure the efficiency of the SST changes in response to the equatorial zonal mean thermocline anomaly and the efficiency of the recharge-discharge of the equatorial thermocline changes in response to the SST anomalies induced off-equatorial wind stress anomaly, respectively. We further delineate that the $F$ factor mainly comes from zonal advective feedback and thermocline feedback, and it can be semianalytically related to the zonal SST gradient and upwelling in the mean state with compounding effects from the ocean-atmosphere coupling and thermocline sharpness. In particular, the approximate formulation of the $F$ factor combines the multiple effects from both mean state and coupling processes into a succinct measure that controls ENSO periodicity. The $B$ factor comes from the compounding effect of the two processes that relate the ENSO-induced wind stress curl difference along the north and south of the equator and the further induced recharge-discharge of the equatorial heat content.

As an approximate dynamic quantification of ENSO periodicity, the Wyrtki index roughly captures the observed main periodicity of ENSO and the wide range of ENSO periodicity in the climate model simulations, with the intermodel correlation reaching 0.86 . The sources for ENSO periodicity biases can also

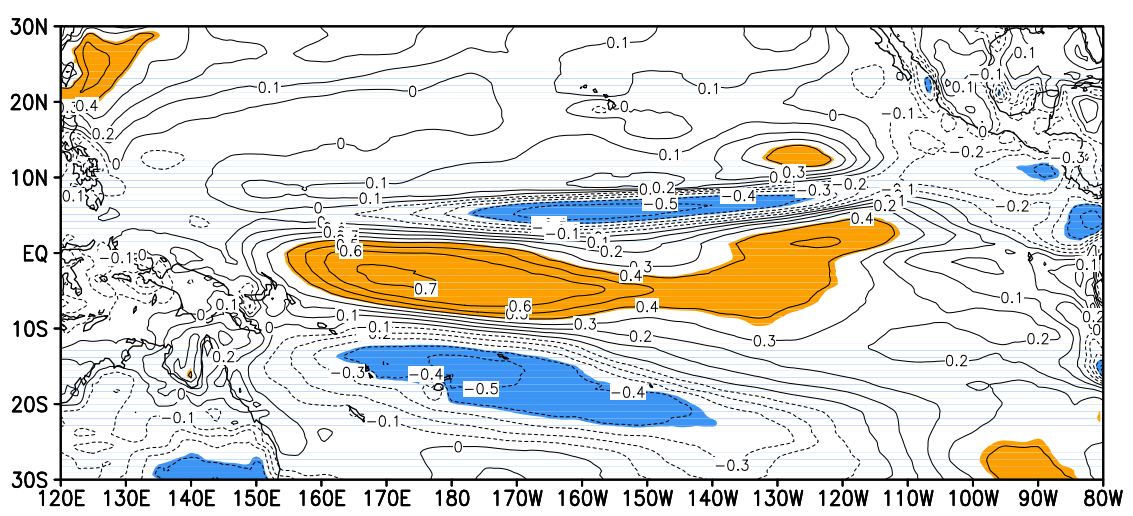

FIG. 11. The pattern of correlation coefficients (nondimensional) between the intermodel $B_{1}$ factor $\left(\mathrm{Pa} \mathrm{m}^{-1}{ }^{\circ} \mathrm{C}^{-1}\right)$ and intermodel ENSO-induced wind stress $\left(\mathrm{Pa}^{\circ} \mathrm{C}^{-1}\right)$. Correlation coefficients that are significant at the $95 \%$ confidence level from the Student's $t$ test are shaded. 

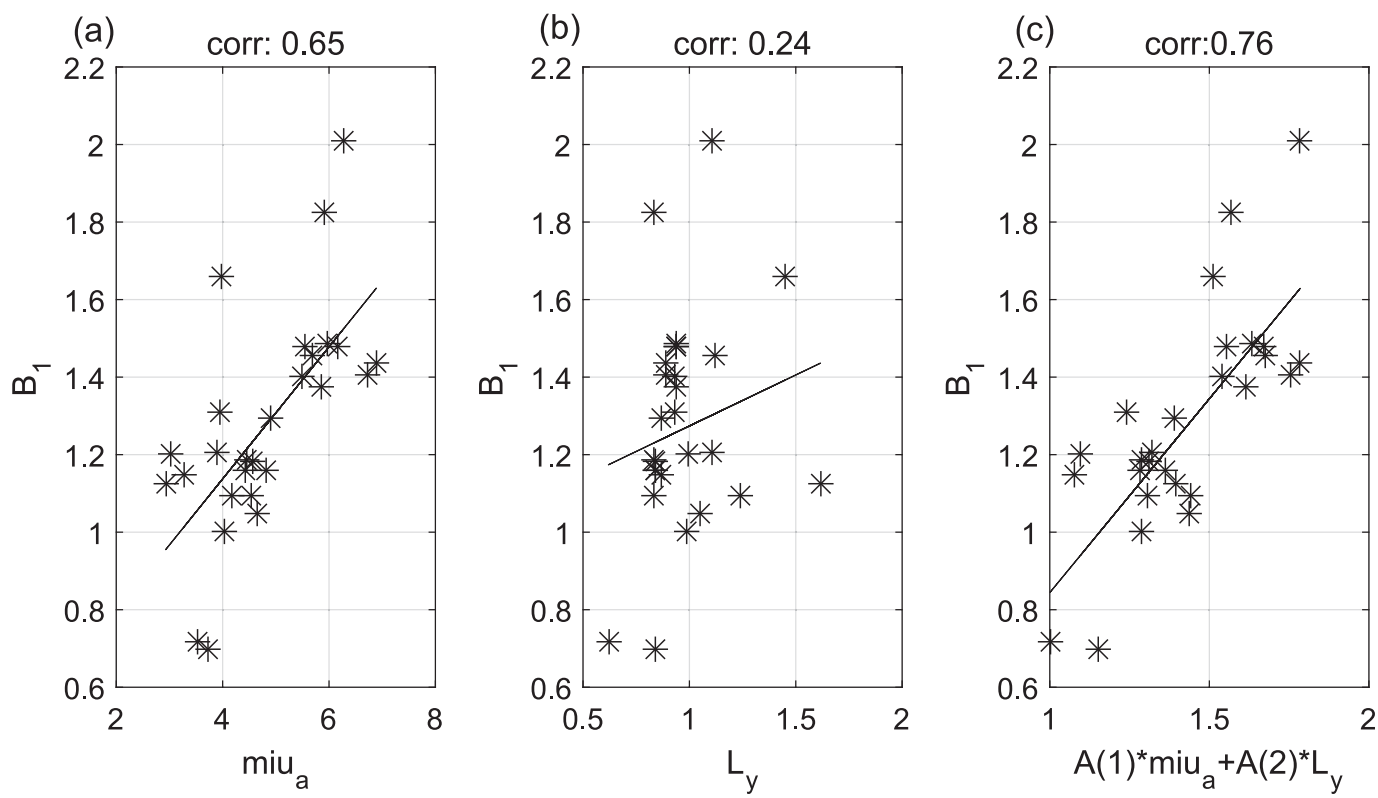

FIG. 12. Scatterplots for the intermodel $B_{1}$ factor $\left(10^{-8} \mathrm{~Pa} \mathrm{~m}^{-1}{ }^{\circ} \mathrm{C}^{-1}\right)$ against (a) the intermodel parameter $\mu_{a}\left(10^{-3} \mathrm{~m} \mathrm{~s}^{-1} \mathrm{~Pa}^{-1}\right)$, (b) the intermodel meridional width of wind stress curl $\left(10^{6} \mathrm{~m}\right)$, and (c) their linear combination $\left(10^{-8} \mathrm{~Pa} \mathrm{~m}^{-1}{ }^{\circ} \mathrm{C}^{-1}\right)$, with the linear fitting lines indicated. The numbers at the top of each panel denote the correlation coefficients.

be analyzed using the Wyrtki index. For example, the short ENSO period in BCC_CSM1.1(m) can be attributed to the larger $F$; the long ENSO period in HadGEM2-ES is caused by the small $B$ factor. It is shown that the spread of simulated ENSO periodicity in the CMIP5 models results from the biases in mean state and several key parameters. Specifically, the intermodel zonal advective feedback $F_{\text {adv }}$ is mainly caused by the intermodel biases in the parameter $\beta_{\mathrm{uh}}$, while the intermodel biases in thermocline feedback $F_{\text {th }}$ mainly result from both the intermodel spread of the parameter $a_{h}$ and the mean upwelling. The intermodel $B$ factor comes from both the biases in the ENSO-induced wind stress curl and the further induced thermocline tendency.

Our current formulation of the Wyrtki index did not take into consideration the contribution of nonlinear processes to ENSO periodicity, which may be significant (Jin 1997b; Eccles and Tziperman 2004). The nonlinear effect on ENSO periodicity in principle can be taken into consideration by examining the contributions of the nonlinear dynamic heating and other nonlinearity in the coupled system to ENSO periodicity. We have also ignored the impact of the background annual cycle on ENSO periodicity, although its impact may be limited, as noted in Jin et al. (1996). Despite these limitations, the linear Wyrtki index may thus serve as a useful tool for studying ENSO periodicity and its changes under different climate conditions in the past and future.

Acknowledgments. This work is jointly supported by China Meteorological Special Program (GYHY201506013), National Key R\&D Program of China (2016YFA0602100), U.S. National Science Foundation (NSF) Grant AGS1406601, U.S. Department of Energy (DOE) Grant DESC000511, and National Science Foundation of China (41605116). The authors declare no conflicts of interest. We thank Dietmar Dommenget and other two anonymous reviewers who helped to improve this paper.

\section{REFERENCES}

An, S.-I., and F.-F. Jin, 2000: An eigen analysis of the interdecadal changes in the structure and frequency of ENSO mode. Geophys. Res. Lett., 27, 2573-2576, https://doi.org/10.1029/ 1999GL011090.

- , and B. Wang, 2000: Interdecadal change of the structure of the ENSO mode and its impact on the ENSO frequency. J. Climate, 13, 2044-2055, https://doi.org/10.1175/1520-0442 (2000) $013<2044:$ ICOTSO $>2.0$. CO;2.

_ , and F.-F. Jin, 2001: Collective role of thermocline and zonal advective feedbacks in the ENSO mode. J. Climate, 14, 3421-3432, https://doi.org/10.1175/1520-0442(2001)014<3421: CROTAZ $>2.0$.CO;2.

,-- , and I.-S. Kang, 1999: The role of zonal advection feedback in phase transition and growth of ENSO in the Cane-Zebiak model. J. Meteor. Soc. Japan, 77, 1151-1160, https://doi.org/10.2151/jmsj1965.77.6_1151. 
— E. S. Heo, and S. T. Kim, 2017: Feedback process responsible for intermodel diversity of ENSO variability. Geophys. Res. Lett., 44, 4272-4279, https://doi.org/10.1002/2017GL073203.

Battisti, D. S., and A. C. Hirst, 1989: Interannual variability in a tropical atmosphere-ocean model: Influence of the basic state, ocean geometry and nonlinearity. J. Atmos. Sci., 46, 1687-1712, https://doi.org/10.1175/1520-0469(1989)046<1687: IVIATA $>2.0 . \mathrm{CO} ; 2$.

Behringer, D. W., M. Ji, and A. Leetmaa, 1998: An improved coupled model for ENSO prediction and implications for ocean initialization. Part I: The ocean data assimilation system. Mon. Wea. Rev., 126, 1013-1021, https://doi.org/10.1175/ 1520-0493(1998)126<1013:AICMFE > 2.0.CO;2.

Bejarano, L., and F.-F. Jin, 2008: Coexistence of equatorial coupled modes of ENSO. J. Climate, 21, 3051-3067, https://doi.org/ 10.1175/2007JCLI1679.1.

Bellenger, H., E. Guilyardi, J. Leloup, M. Lengaigne, and J. Vialard, 2014: ENSO representation in climate models: From CMIP3 to CMIP5. Climate Dyn., 42, 1999-2018, https:// doi.org/10.1007/s00382-013-1783-z.

Bjerknes, J., 1969: Atmospheric teleconnections from the equatorial Pacific. Mon. Wea. Rev., 97, 163-172, https://doi.org/ 10.1175/1520-0493(1969)097<0163:ATFTEP > 2.3.CO;2.

Cane, M. A., M. Münnich, and S. E. Zebiak, 1990: A study of selfexcited oscillations of the tropical ocean-atmosphere system. Part I: Linear analysis. J. Atmos. Sci., 47, 1562-1577, https:// doi.org/10.1175/1520-0469(1990)047<1562:ASOSEO>2.0.CO;2.

Capotondi, A., A. Wittenberg, and S. Masina, 2006: Spatial and temporal structure of tropical Pacific interannual variability in 20th century coupled simulations. Ocean Modell., 15, 274-298, https://doi.org/10.1016/j.ocemod.2006.02.004.

Clarke, A. J., S. Van Gorder, and G. Colantuono, 2007: Wind stress curl and ENSO discharge/recharge in the equatorial Pacific. J. Phys. Oceanogr., 37, 1077-1091, https://doi.org/10.1175/ JPO3035.1.

Dommenget, D., S. Haase, T. Bayr, and C. Frauen, 2014: Analysis of the Slab Ocean El Niño atmospheric feedbacks in observed and simulated ENSO dynamics. Climate Dyn., 42, 3187-3205, https://doi.org/10.1007/s00382-014-2057-0.

Eccles, F., and E. Tziperman, 2004: Nonlinear effects on ENSO's period. J. Atmos. Sci., 61, 474-482, https://doi.org/10.1175/ 1520-0469(2004)061<0474:NEOEP $>2.0$.CO;2.

Fedorov, A. V., and S. G. Philander, 2000: Is El Niño changing? Science, 288, 1997-2002, https://doi.org/10.1126/ science.288.5473.1997.

_ , and —_, 2001: A stability analysis of tropical oceanatmosphere interactions: Bridging measurements and theory for El Niño. J. Climate, 14, 3086-3101, https://doi.org/10.1175/ 1520-0442(2001)014<3086:ASAOTO>2.0.CO;2.

Jin, F.-F., 1997a: An equatorial ocean recharge paradigm for ENSO. Part I: Conceptual model. J. Atmos. Sci., 54, 811-829, https://doi.org/10.1175/1520-0469(1997)054<0811: AEORPF $>2.0 . \mathrm{CO} ; 2$.

- 1997b: An equatorial ocean recharge paradigm for ENSO. Part II: A stripped-down coupled model. J. Atmos. Sci., 54, 830-847, https://doi.org/10.1175/1520-0469(1997)054<0830: AEORPF $>2.0 . \mathrm{CO} ; 2$.

, and J. D. Neelin, 1993a: Modes of interannual tropical oceanatmosphere interaction-A unified view. Part I: Numerical results. J. Atmos. Sci., 50, 3477-3503, https://doi.org/10.1175/ 1520-0469(1993)050<3477:MOITOI >2.0.CO;2.

__ and —_, 1993b: Modes of interannual tropical oceanatmosphere interaction-A unified view. Part III: Analytical results in fully coupled cases. J. Atmos. Sci., 50, 3523-3540, https://doi.org/10.1175/1520-0469(1993)050<3523:

MOITOI $>2.0 . \mathrm{CO} ; 2$.

_ , and S.-I. An, 1999: Thermocline and zonal advective feedbacks within the equatorial ocean recharge oscillator model for ENSO. Geophys. Res. Lett., 26, 2989-2992, https://doi.org/ 10.1029/1999GL002297.

_ J. D. Neelin, and M. Ghil, 1996: El Niño/Southern Oscillation and the annual cycle: Subharmonic frequency-locking and aperiodicity. Physica D, 98, 442-465, https://doi.org/10.1016/ 0167-2789(96)00111-X.

_, S. T. Kim, and L. Bejarano, 2006: A coupled-stability index of ENSO. Geophys. Res. Lett., 33, L23708, https://doi.org/ 10.1029/2006GL027221.

Kang, I.-S., and S.-I. An, 1998: Kelvin and Rossby wave contributions to the SST oscillation of ENSO. J. Climate, 11, 24612469, https://doi.org/10.1175/1520-0442(1998)011<2461: KARWCT $>2.0 . \mathrm{CO} ; 2$.

Kim, S.-T., and F.-F. Jin, 2011: An ENSO stability analysis. Part II: Results from the twentieth and twenty-first century simulations of the CMIP3 models. Climate Dyn., 36, 1609-1627, https://doi.org/10.1007/s00382-010-0872-5.

—_, W. Cai, F.-F. Jin, and J.-Y. Yu, 2014: ENSO stability in coupled climate models and its association with mean state. Climate Dyn., 42, 3313-3321, https://doi.org/10.1007/ s00382-013-1833-6.

Kirtman, B. P., 1997: Oceanic Rossby wave dynamics and the ENSO period in a coupled model. J. Climate, 10, 16901704, https://doi.org/10.1175/1520-0442(1997)010<1690: ORWDAT $>2.0 . \mathrm{CO} ; 2$.

Lloyd, J., E. Guilyardi, and H. Weller, 2011: The role of atmosphere feedbacks during ENSO in the CMIP3 models. Part II: Using AMIP runs to understand the heat flux feedback mechanisms. Climate Dyn., 37, 1271-1292, https://doi.org/ 10.1007/s00382-010-0895-y.

MacMynowski, D. G., and E. Tziperman, 2008: Factors affecting ENSO's period. J. Atmos. Sci., 65, 1570-1586, https://doi.org/ 10.1175/2007JAS2520.1.

McCreary, J. P., 1983: A model of tropical ocean-atmosphere interaction. Mon. Wea. Rev., 111, 370-387, https://doi.org/ 10.1175/1520-0493(1983)111<0370:AMOTOA > 2.0.CO;2.

Morlet, J., G. Arens, E. Fourgeau, and D. Glard, 1982: Wave propagation and sampling theory-Part I: Complex signal and scattering in multilayered media. Geophysics, 47, 203-221, https://doi.org/10.1190/1.1441328.

Neelin, J. D., 1991: The slow sea surface temperature mode and the fast-wave limit: Analytic theory for tropical interannual oscillations and experiments in a hybrid coupled model. J. Atmos. Sci., 48, 584-606, https://doi.org/10.1175/1520-0469 (1991)048<0584:TSSSTM $>2.0$. CO;2.

, and F.-F. Jin, 1993: Modes of interannual tropical oceanatmosphere interaction-A unified view. Part II: Analytical results in the weak-coupling limit. J. Atmos. Sci., 50, 3504-3522, https://doi.org/10.1175/1520-0469(1993)050<3504: MOITOI $>2.0 . \mathrm{CO} ; 2$.

Philander, S. G., T. Yamagata, and R. C. Pacanowski, 1984: Unstable air-sea interactions in the tropics. J. Atmos. Sci., 41, 604-613, https://doi.org/10.1175/1520-0469(1984)041<0604: UASIIT $>2.0 . \mathrm{CO} ; 2$.

Stuecker, M. F., A. Timmermann, F.-F. Jin, S. McGregor, and H.-L. Ren, 2013: A combination mode of the annual cycle and the El Niño/Southern Oscillation. Nat. Geosci., 6, 540544, https://doi.org/10.1038/ngeo1826. 
Suarez, M. J., and P. S. Schopf, 1988: A delayed action oscillator for ENSO. J. Atmos. Sci., 45, 3283-3287, https://doi.org/10.1175/ 1520-0469(1988)045<3283:ADAOFE > 2.0.CO;2.

Syu, H. H., and J. D. Neelin, 2000: ENSO in a hybrid coupled model. Part I: Sensitivity to physical parameterizations. Climate Dyn., 16, 19-34, https://doi.org/10.1007/ PL00007920.

Taylor, K. E., R. J. Stouffer, and G. A. Meehl, 2012: An overview of CMIP5 and the experiment design. Bull. Amer. Meteor. Soc., 93, 485-498, https://doi.org/10.1175/BAMS-D-11-00094.1.

Timmermann, A., J. Oberhuber, A. Bacher, M. Esch, M. Latif, and E. Roeckner, 1999: Increased El Niño frequency in a climate model forced by future greenhouse warming. Nature, 398, 694-697, https://doi.org/10.1038/19505.

Wang, G., D. Dommenget, and C. Frauen, 2015: An evaluation of the CMIP3 and CMIP5 simulations in their skill of simulating the spatial structure of SST variability. Climate Dyn., 44, 95-114, https://doi.org/10.1007/s00382-014-2154-0.

Wyrtki, K., 1985: Water displacements in the Pacific and the genesis of El Niño cycles. J. Geophys. Res., 90, 7129-7132, https:// doi.org/10.1029/JC090iC04p07129.

Zebiak, S. E., and M. A. Cane, 1987: A model El Niño-Southern Oscillation. Mon. Wea. Rev., 115, 2262-2278, https://doi.org/ 10.1175/1520-0493(1987)115<2262:AMENO>2.0.CO;2. 